\title{
Comparison of HPV Testing and Colposcopy in Detecting Cervical Dysplasia in Patients With Cytological Abnormalities
}

\author{
JOANNA ŚWIDERSKA-KIEC, KRZYSZTOF CZAJKOWSKI, JULIA ZARĘBA-SZCZUDLIK, \\ JOANNA KACPERCZYK-BARTNIK, PAWEŁ BARTNIK and EWA ROMEJKO-WOLNIEWICZ \\ $2^{\text {nd }}$ Department of Obstetrics and Gynaecology, Medical University of Warsaw, Warsaw, Poland
}

\begin{abstract}
Aim: The aim of the study was to compare the diagnostic value of HPV testing and colposcopy in patients with abnormal cytology results. Patients and Methods: A total of 186 women with cytological abnormalities were included in the study. The patients underwent colposcopy examinations and DNA HPV testing of cervical smear with genotyping. Results: The HPV test was demonstrated to be more sensitive (79.4\%) than specific (60.2\%) and was more sensitive than colposcopy for detecting CIN changes $(79.4 \%$ vs. $73.7 \%)$. Combined tests achieved a high sensitivity (90.9\%) and negative predictive value (96.1\%) in detecting patients with CIN2+ and demonstrated the highest positive predictive value $(77.3 \%)$ for detecting CIN1+. Colposcopy had a very good specificity $(83.5 \%)$ and positive predictive value $(71.2 \%)$ in finding CIN1+ cases. Conclusion: HPV tests showed a higher sensitivity than colposcopy, but colposcopy results presented higher specificity. Combining HPV testing and colposcopy proved to be the most efficient method for detecting CIN lesions.
\end{abstract}

The human papillomavirus (HPV) poses an important epidemiological and clinical problem worldwide, particularly with respect to the development of cervical cancer and other diseases (1). HPV infection is the primary cause of cervical neoplasia and cervical cancer. Over 40 HPV genotypes that are known to cause infections in the anogenital area have been identified (2). These genotypes include high-risk types, which are responsible for the progression to cervical neoplasia and cancer, and low-risk types, which rarely lead to cancer, but are

This article is freely accessible online.

Correspondence to: Julia Zaręba-Szczudlik, 2nd Department of Obstetrics and Gynecology, Medical University of Warsaw, Karowa Street 2, 00-315 Warsaw, Poland. Tel: +48 225966421, Fax: +48 225966487, e-mail: juliaszmed@wp.pl

Key Words: Cervical intraepithelial neoplasia, colposcopy, diagnosis, papillomaviridae. capable of causing genital warts. A persistent infection with oncogenic HPV is considered to be the most important predictor of CIN 2 or 3 or for the progression to cancer. The high-risk genotypes are associated with over $80 \%$ of cervical carcinomas and CIN2/3 $(3,4)$. Globally, the most common and clinically relevant genotypes in the population are HPV 16 and 18, that account for more than $70 \%$ of all cervical cancer cases, 41-67\% of high-grade cervical lesions and 16$32 \%$ of low-grade cervical lesions $(3,5)$. Among the nononcogenic HPV genotypes, types 6 and 11 are the most common and are associated with more than $90 \%$ of genital infections (6). These types are primarily responsible for recurrent respiratory papillomatosis (RRP) and for a small proportion of low-grade cervical cell abnormalities (7).

The prevalence of HPV genotypes depends on the geographic region and demographic factors $(3,8-11)$. In the Polish population, HPV genotypes 16 and 18 are the most prevalent and are observed in more than $72.4 \%$ of women with cervical cancer (12-14). The incidence rate and mortality from cervical cancer vary depending on the existing screening program with regard to cytology, colposcopy or HPV testing. In Poland, a cytology examination is recommended for all women between 25 and 59 years old at 3-year intervals. However, cytology alone is a subjective method with divergent diagnostic values for sensitivity that range from 20 to $75 \%$ and specificity (35$90 \%$ ) in detecting CIN2+. Moreover, a high discrepancy in the cytology results can be observed between laboratories. Women with abnormal smear findings should be referred for a colposcopy or biopsy. Colposcopy examination is very efficient for detecting high-grade cervical changes, but has poor reproducibility and a lower specificity for detecting patients with CIN1/2 (15-18). Thus, HPV testing appears to be a good solution which might improve the efficacy of detection in all CIN cases. The challenge is to find the correct test that will allow a diagnosis of only clinically relevant infections without over-treating patients with transient HPV infections that may be cured spontaneously.

In this study, we selected a group of patients who attended a colposcopy clinic and had abnormal cytology results to 
compare the diagnostic validity of two screening tests, namely, colposcopy examination and DNA HPV testing with genotyping to detect low- and high-grade dysplasia (CIN) and cervical cancer. We discuss the best combination of these methods to identify women with abnormal cytology who are at a high risk of developing cervical cancer.

\section{Patients and Methods}

Patients. In the present study, we included 186 patients with abnormal cytology smear results. We determined the women's ages, number of pregnancies and deliveries, history of cervical diseases or sexual infections and lifestyle factors such as smoking, contraceptive use and the number of sexual partners. The women were classified according to the following PAP smear results (based on the Bethesda System): high-grade squamous intraepithelial lesions (HSIL), $n=19$; atypical squamous cells, cannot exclude HSIL (ASC-H), n=7; lowgrade squamous intraepithelial lesions (LSIL), $\mathrm{n}=85$; atypical squamous cells of undetermined significance (ASCUS), $n=71$; and atypical glandular cells of undetermined significance (AGUS), $n=4$. To examine the degree of cervical pathology more thoroughly, subsequent diagnostic procedures including colposcopy and DNA HPV virus detection were performed.

All examinations were performed in the colposcopy outpatient clinic at the tertiary referral center. All women agreed to participate in the study, and we obtained approval to conduct the study from the local Bioethical Committee. A cervical swab was obtained from each patient for DNA HPV virus testing, and a colposcopy examination was performed to evaluate any abnormalities in the cytology findings. The results from the HPV tests were classified as positive or negative; in the case of positive results, the HPV genotype was determined. The colposcopy results were classified as negative, suspected CIN or cancer, or unsatisfactory. Finally, the patients with suspicious colposcopy results underwent a punch biopsy taken from the part of the cervix in question. Women with negative or unsatisfactory results of colposcopy were observed and referred for repeat cytology testing. Finally, the patients were classified into the healthy (with no suggestion of cervical dysplasia or cancer) or unhealthy (with cervical lesions of CIN1, CIN2, or CIN3 degree or cervical cancer) categories.

Laboratory procedures. All cervical smears were obtained with a cytological brush, collected in $1 \mathrm{ml}$ of lysis buffer and stored at $4{ }^{\circ} \mathrm{C}$ until HPV testing could be conducted in the laboratory. The DNA was isolated using the Tissue DNA Purification Kit (Eurx, Gdansk, Poland). The DNA samples were stored at $-20^{\circ} \mathrm{C}$, according to the manufacturer's instructions. DNA concentrations of 50 to $100 \mathrm{ng} / \mu \mathrm{l}$ were used for the DNA amplification reaction. The commercial BIOPAP-Detection Kit (Biotools B\&M Labs, Madrid, Spain) was used as recommended to detect HPV DNA by standard PCR and determine the virus types. For the PCR reaction, two primer sets were used. One pair of primers (GEN1 and GEN2) was hybridised with sequences that are common to all tested HPV genotypes, namely, the L1 and L2 genes; thus, amplification with this primer pair indicated the presence of HPV. The second pair of primers (ONC1 and $\mathrm{ONC} 2$ ) was hybridised with sequences specific for the oncogenic HPV genotypes, the E6 and E7 genes. The final reaction volume was $25 \mu \mathrm{l}$, and it contained $10 \mu \mathrm{l}$ of the isolated DNA, 50 $\mathrm{mM} \mathrm{MgCl}_{2}$ solution, $1 \mathrm{U}$ Perpetual Taq DNA Polymerase (Eurx,
Gdansk, Poland) and the HPV Mixture/Tris-HCl solution, which contained $<10 \%$ glycerol; $\mathrm{KCl} ;<0.001 \%$ dATP, dCTP, dGTP and dTTP; and the primers. The PCR conditions for the amplification of HPV DNA were as follows: $5 \mathrm{~min}$ at $94^{\circ} \mathrm{C} ; 35$ cycles of $30 \mathrm{sec}$ duration each at $94^{\circ} \mathrm{C}, 60 \mathrm{sec}$ at $55^{\circ} \mathrm{C}$ and $60 \mathrm{sec}$ at $72^{\circ} \mathrm{C}$; and elongation for $10 \mathrm{~min}$ at $72^{\circ} \mathrm{C}$. The analysis of the amplified PCR products was performed by electrophoresis in $2 \%$ agarose gel, specifically, Agarose Basica LE (Abo, Gdansk, Poland) with ethidium bromide in the $0.5 \times$ TBE buffer. The presence of HPV was indicated by a band of approximately $450 \mathrm{bp}$, and if oncogenic HPV genotypes were present in the sample, an additional band of $250 \mathrm{bp}$ was present. An experiment was performed with the following separate controls: positive controls (sequences of generic and oncogenic HPVs), negative PCR controls (nuclease-free $\mathrm{H}_{2} \mathrm{O}$ ) and negative DNA isolation controls. To genotype the 33 HPV types, the restriction fragment length polymorphism (RFLP) method was used. Positive PCR amplification products were digested using 5 different specific restriction endonucleases that were designed by Biotools. For the restriction analysis, the products of each digestion were analysed by electrophoresis in $3 \%$ agarose gel, specifically, Agarose Reducta NU (Abo, Gdansk, Poland) stained with ethidium bromide. The patterns that were obtained indicated the presence of HPV and its genotype.

Statistical analysis. The performance characteristics: sensitivity, specificity, negative predictive value (NPV), and positive predictive value (PPV) of the HPV test, colposcopy and both tests together in detecting CIN1+ and CIN2+ changes were calculated for all patients with abnormal cytology results. The reference method used for obtaining the final diagnosis of patients with abnormal Pap smear results as well as for the assessment of HPV testing and colposcopy characteristics was histology.

For determining sensitivity and specificity of colposcopy, positive colposcopy results in patients with a positive final diagnosis (histology) were considered as true positives; positive colposcopy results in patients with negative histology results were considered as false positives; negative colposcopy results in patients with negative histology results were considered as true negatives; and negative colposcopy results in patients with positive histology results were considered as false negatives. Unsatisfactory colposcopy results were excluded from the analysis.

For determining sensitivity and specificity of HPV testing, positive HPV results in patients with positive final diagnosis (histology) were considered as true positives; positive HPV results in patients with negative histology results were considered as false positives; negative HPV results in patients with negative histology results were considered as true negatives; and negative HPV results in patients with positive histology results were considered as false negatives. Both high risk and low risk HPV testing results were included in the analysis.

\section{Results}

Patient characteristics. The median age of the patients was 35.8 years (range $=18-79$ years). Of the 186 women enrolled in the study, $82(44.1 \%)$ smoked cigarettes, 104 (55.9\%) were taking contraceptive pills, $110(59.1 \%)$ had a history of vaginal infections, $58(31.2 \%)$ had a history of urogenital infections, and $104(55.9 \%)$ had ectopic changes on the cervix. 
Table I. Distribution of colposcopic and HPV infection results, according to cytology smear results.

\begin{tabular}{|c|c|c|c|c|c|c|c|c|}
\hline \multirow{2}{*}{$\begin{array}{l}\text { PAP } \\
\text { results }\end{array}$} & \multirow[t]{2}{*}{$\mathrm{N}$} & \multicolumn{3}{|c|}{ Colposcopy results } & \multirow{2}{*}{ 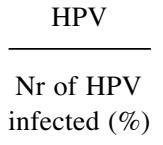 } & \multicolumn{3}{|c|}{ Distribution of HPV types } \\
\hline & & $\begin{array}{l}\text { Suspected } \\
(\%)\end{array}$ & $\begin{array}{c}\text { Negative } \\
(\%)\end{array}$ & $\begin{array}{c}\text { Unsatisfactory } \\
(\%)\end{array}$ & & $\begin{array}{l}\mathrm{HR} \\
(\%)\end{array}$ & $\begin{array}{l}\mathrm{LR} \\
(\%)\end{array}$ & $\begin{array}{c}\text { Co-infection } \\
(\%)\end{array}$ \\
\hline HSIL & 19 & $\begin{array}{c}12 \\
(63.2 \%)\end{array}$ & $\begin{array}{c}5 \\
(26.3 \%)\end{array}$ & $\begin{array}{c}2 \\
(10.5 \%)\end{array}$ & $\begin{array}{c}14 \\
(73.7 \%)\end{array}$ & $\begin{array}{c}7 \\
(50.0 \%)\end{array}$ & $\begin{array}{c}4 \\
(28.6 \%)\end{array}$ & $\begin{array}{c}3 \\
(21.4 \%)\end{array}$ \\
\hline ASC-H & 7 & $\begin{array}{c}3 \\
(42.9 \%)\end{array}$ & $\begin{array}{c}1 \\
(14.3 \%)\end{array}$ & $\begin{array}{c}3 \\
(42.9 \%)\end{array}$ & $\begin{array}{c}3 \\
(42.7 \%)\end{array}$ & $\begin{array}{c}2 \\
(66.7 \%)\end{array}$ & $\begin{array}{c}1 \\
(33.3 \%)\end{array}$ & - \\
\hline LSIL & 85 & $\begin{array}{c}30 \\
(35.3 \%)\end{array}$ & $\begin{array}{c}48 \\
(56.5 \%)\end{array}$ & $\begin{array}{c}7 \\
(8.2 \%)\end{array}$ & $\begin{array}{c}56 \\
(65.9 \%)\end{array}$ & $\begin{array}{c}40 \\
(71.4 \%)\end{array}$ & $\begin{array}{c}5 \\
(8.9 \%)\end{array}$ & $\begin{array}{c}11 \\
(19.6 \%)\end{array}$ \\
\hline ASC-US & 71 & $\begin{array}{c}14 \\
(19.7 \%)\end{array}$ & $\begin{array}{c}45 \\
(63.4 \%)\end{array}$ & $\begin{array}{c}12 \\
(16.9 \%)\end{array}$ & $\begin{array}{c}26 \\
(36.6 \%)\end{array}$ & $\begin{array}{c}15 \\
(57.7 \%)\end{array}$ & $\begin{array}{c}9 \\
(34.6 \%)\end{array}$ & $\begin{array}{c}2 \\
(7.7 \%)\end{array}$ \\
\hline AGUS & 4 & 0 & $\begin{array}{c}2 \\
(50.0 \%)\end{array}$ & $\begin{array}{c}2 \\
(50.0 \%)\end{array}$ & 0 & - & - & - \\
\hline Total & 186 & $\begin{array}{c}59 \\
(31.7 \%)\end{array}$ & $\begin{array}{c}101 \\
(54.3 \%)\end{array}$ & $\begin{array}{c}26 \\
(14.0 \%)\end{array}$ & $\begin{array}{c}99 \\
(53.2 \%)\end{array}$ & $\begin{array}{c}64 \\
(64.7 \%)\end{array}$ & $\begin{array}{c}19 \\
(19.2 \%)\end{array}$ & $\begin{array}{c}16 \\
(16.2 \%)\end{array}$ \\
\hline
\end{tabular}

Distribution of HPV and colposcopy results in the study population

Colposcopy. A total of 101 patients (54\%) had negative colposcopy results, whereas 59 patients $(32 \%)$ had suspicious results and 26 women (14\%) had colposcopy results which were deemed unsatisfactory. Suspicious colposcopy results were primarily observed in patients from the HSIL group (63.2\%); the least likely to have such results were in the ASCUS group (19.7\%), and no patient in the AGUS group had these results. Negative colposcopy results were predominantly found in patients with ASCUS (63.4\%) and LSIL (56.5\%) cytology results (Table I).

$H P V$. Out of the 186 women, 99 (53.2\%) were found to be infected with any HPV type. Infections were observed most frequently in women with cytological results which revealed HSIL (73.7\%) and LSIL (65.9\%). No HPV was found in the 4 patients with AGUS cytology. In the ASCUS group, HPV was detected in $36.6 \%$ of patients, whereas $42.7 \%$ of those in the ASC-H group had detectable HPV. The distribution of HPV infections in the different cytological groups is shown in Figure 1. Among all of the HPV-positive patients, single genotypes were most frequently detected: high-risk types were observed in $64.7 \%$, and low-risk types were found in $19.2 \%$. Multiple infections (double or triple) were identified in $16.2 \%$ of specimens. Considering the different cytology groups, the high-risk genotypes were the most frequent among patients with LSIL and ASC-H and were detected in $71.4 \%$ and $66.7 \%$ of such patients, respectively. Low-risk genotypes were most common in patients with an ASCUS cytology results and comprised $34.6 \%$ of the positive HPV cases. The distribution of colposcopy and HPV virus and its genotype in women according to their cytological smear results is shown in Table I. HPV infections were most common in women in age group 18-29 years, in whom the virus was detected in $76.2 \%$ of the patients. The lowest number of infections ( $25 \%$ of patients) was observed in the group aged over 60 years. The frequency of HPV infection according to the age group is shown in Figure 2. A total of 117 patterns were detected using the restriction enzyme polymorphism technique from $99 \mathrm{HPV}$-infected women. The overall distribution of 21 different HPV genotypes with respect to a cytological diagnosis is shown in Table II In the entire tested population, HPV 16 type was the dominant genotype (23/99 patients). However, we found that oncogenic types 31 (18/99 patients) and 33 (11/99 patients) and low-risk type 30 (11/99 patients) were also common in the study participants. In addition, infections with undefined high- or low-risk genotypes were frequent (10/99 patients).

Final diagnosis in the study population. All patients with abnormal cytology results were assigned a final diagnosis at the end of the study. Most women (123/186, or 66.1\%) were healthy, with no abnormal dysplasia changes, whereas 32 patients were diagnosed with CIN1, 18 with CIN3 and 12 with CIN2. Only 1 patient with LSIL cytology had cervical cancer as their final diagnosis. Healthy patients $(60 / 71$, or $84.5 \%$ ) were primarily found in the ASCUS cytology group, and $4 / 4(100 \%)$ of the women from the AGUS group were healthy. The patients with diagnosed cervical lesions (63 women) had predominantly HSIL results (11/19 patients, or $57.9 \%$ ) and ASC-H results (4/7 women, or $57.1 \%$ ), followed by LSIL results (37/85 patients, or $43.5 \%)$. The distribution of the final result according to the cytological diagnosis is presented in Table III. Among the 18 patients with a diagnosis of CIN3, we found that $16(88.9 \%)$ were infected with any HPV type and that 10 had HPV genotype 16. Of the 12 patients with CIN2, we diagnosed 9 (75.0\%) with 


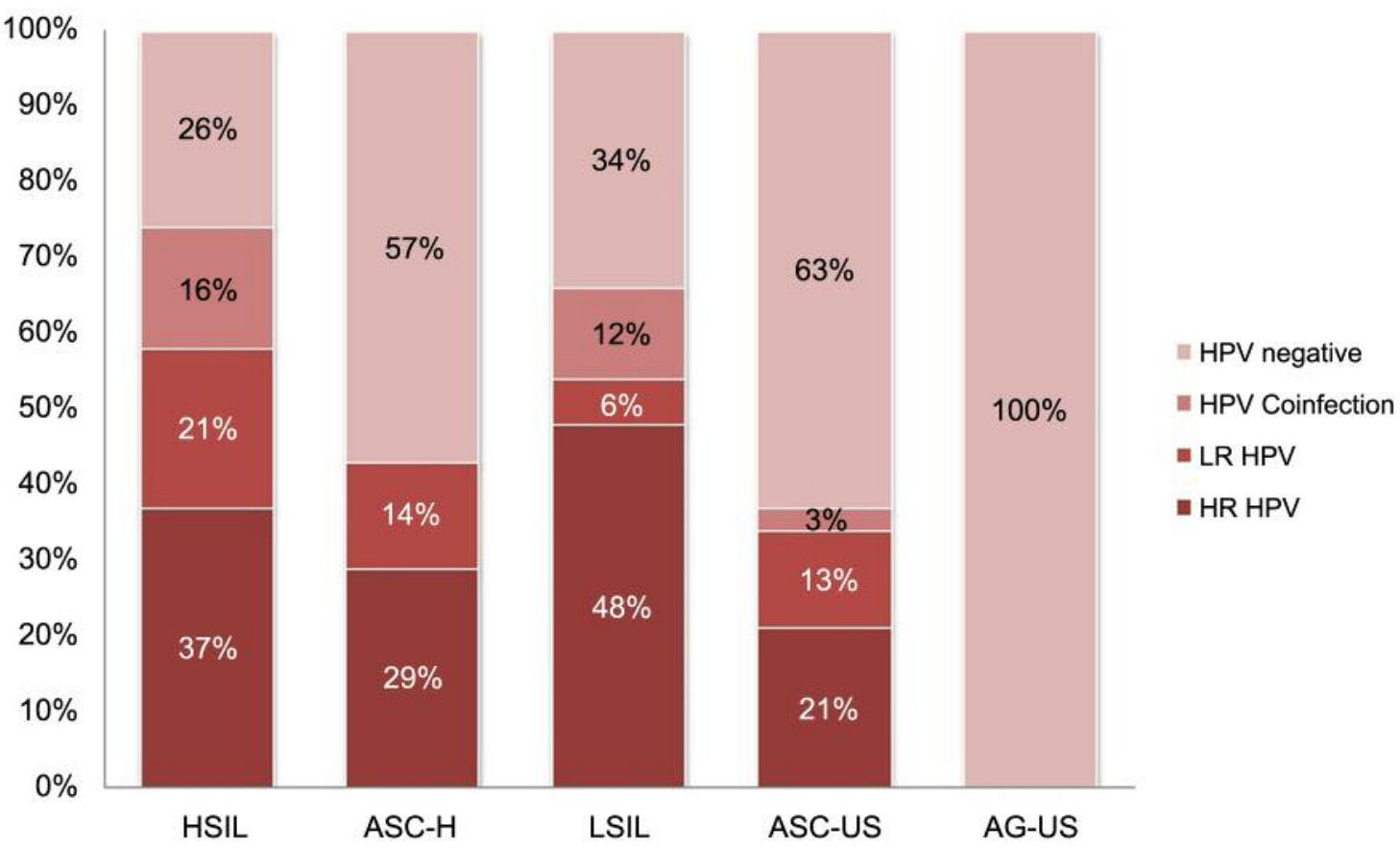

Figure 1. Distribution of the type of HPV infection in patients with different abnormal cytology results.

HPV infection, predominantly the high-risk types, except 1 case of low-risk HPV. In the CIN1 group, $18(56.2 \%)$ women had high-risk HPV infection, 6 (18.7\%) had low-risk HPV and $8(25 \%)$ were negative on the HPV test. The cervical cancer was found in a patient with other high-risk types than HPV 16 or 31.

Comparison of efficacy of DNA HPV testing and colposcopy. The reference method for assessment of DNA HPV testing and colposcopy efficacy was histology. Distribution of colposcopic and HPV infection results, according to final diagnosis (histology) are presented in Table IV. The screening efficacy of both tests, including the combination of colposcopy and HPV testing for CIN, is shown in Table V. We determined that the HPV test is more sensitive than colposcopy for detecting CIN1+ cases, with values of $79.4 \%$ for the HPV test and $73.7 \%$ for colposcopy. For the detection of patients with CIN2+ lesions, the sensitivity was slightly higher for colposcopy $(85.2 \%$ and $83.9 \%$, respectively). The highest values were achieved when the tests were conducted together; specifically, a sensitivity of $89.5 \%$ for detecting cases with CIN1+ was obtained, and a sensitivity of $90.9 \%$ was found for CIN2+. Colposcopy identified women with any dysplasia with the highest specificity, specifically, $83.5 \%$ in CIN1 and $72.9 \%$ in CIN2+. The HPV test was shown to have the lowest specificity: $60.2 \%$ for detecting CIN1+ and $52.9 \%$ for
CIN2+. In terms of the positive predictive value for CIN1+ and CIN2+, the combination of both tests was shown to yield the highest efficacy ( $77.3 \%$ and $45.4 \%$, respectively). In these positive patients, we found 14 cases in the CIN1, 6 in the CIN2, 13 in the CIN3 groups and 1 with cancer. We also observed a different PPV for each cytology, specifically, $100 \%$ (2/2 patients) for the ASC-H group, $80 \%$ (8/10 patients) for the HSIL and $75 \%$ for the LSIL (18/24 patients) and ASCUS (6/8 patients) groups. The HPV test alone had the lowest PPV (50.5\% for the CIN1+ and $26.3 \%$ for the CIN2+ cases) where colposcopy achieved a PPV of $71.2 \%$ for CIN1+ and $39.0 \%$ for CIN2+. Comparing the PPV for each cytology result for the HPV test, we observed the highest PPV of $100 \%$ (3/3 patients) for the ASC-H group and $64.3 \%$ (9/14 patients) for the HSIL group, followed by $53.6 \%$ (30/56 cases) for the LSIL and the lowest PPV of $30.8 \%$ (8/26 cases) for the ASCUS patients. In colposcopy, the highest PPV of $100 \%$ (3/3 patients) was observed in the ASC-H group and $83.3 \%$ (10/12 patients) in the HSIL patients, followed by $70 \%$ (21/30 patients) for the LSIL and $57.1 \%$ (8/14 patients) for the ASCUS group. We also achieved the highest NPV when both tests were conducted together (HPV and colposcopy), specifically, 92.3\% for CIN1+ and $96.1 \%$ for CIN2+. Only 4 patients were diagnosed with dysplasia, with 2 cases of CIN1 and 2 cases of CIN2. The NPV was $100 \%$ in every cytology group except the ASCUS (NPV 96.4\%) and LSIL (84.2\%) groups. 


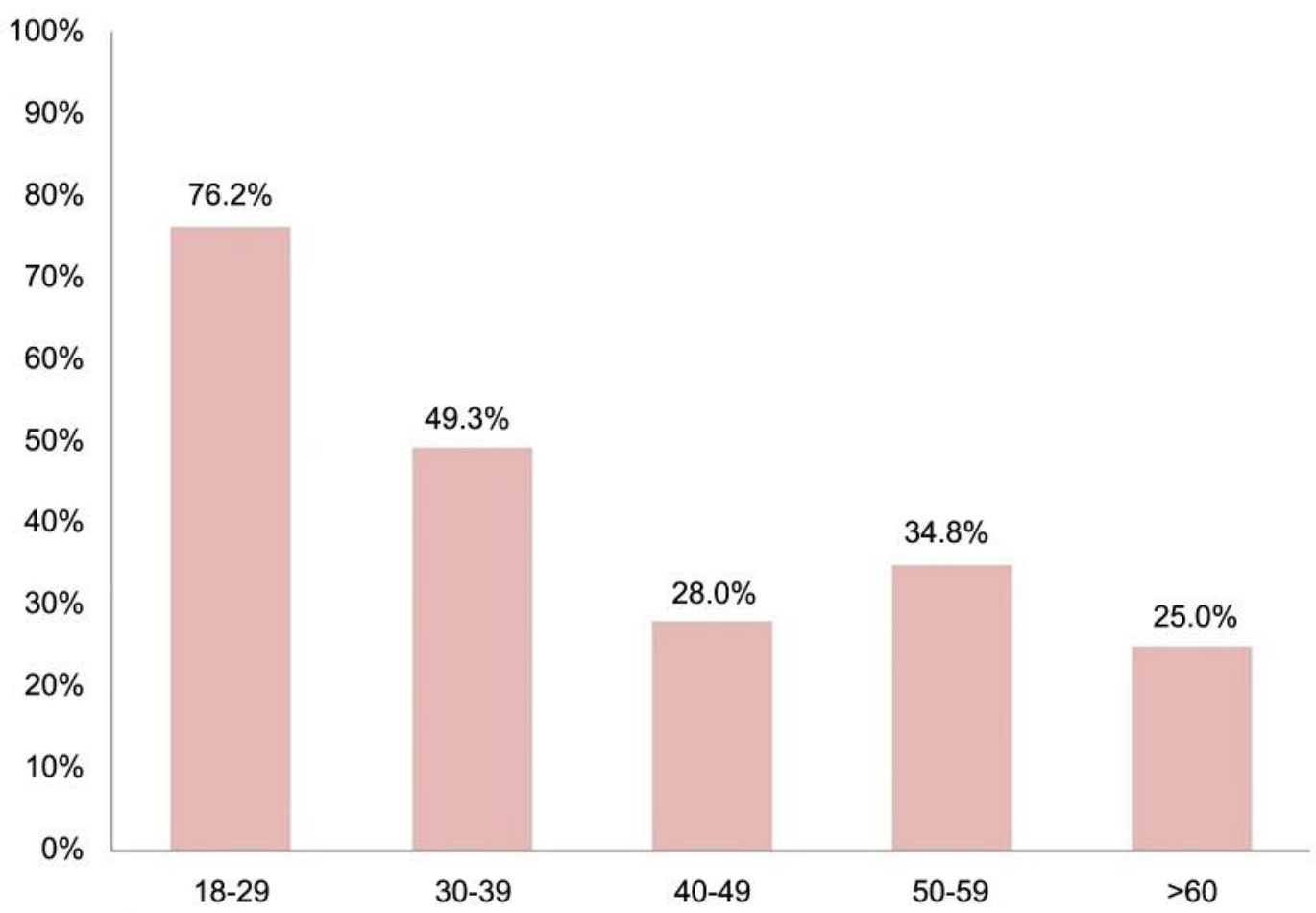

Figure 2. Distribution of HPV infections according to age.

\section{Discussion}

One major finding of this study was that the highest positive and negative predictive values of the HPV test and colposcopy examination were attained when the tests were performed together. When comparing each test completed alone, the PPV was higher for the colposcopy examination (71.2\%) compared to the HPV test $(50.5 \%)$ in detecting any dysplasia $(\mathrm{CIN} 1+)$. Our results are similar to those reported in previous studies $(16,19,20)$ and even higher than those reported in a study from Germany, in which the PPV for the HPV test was $36 \%$; it was $38 \%$ for colposcopy (17). The explanation for this finding may be that a high percentage of the female population acquires latent HPV infection at some point in their lives but most eliminate the virus before cervical dysplasia changes appear. A total $49.5 \%$ of patients with positive HPV tests were ultimately classified as healthy at the end of the study. These transient HPV infections place women at a higher risk for acquiring other urogenital infections or HPV infections of other genotypes in the future. The high PPV of colposcopy was obtained because when using this method, we observed changes in the cervix in real time. However, we noted the unsatisfactory results of colposcopy (26/186 women, $14 \%$ of all cases) that have an impact on the diagnostic process. The coupled tests performed together resulted in the best PPV for detecting CIN1+ cases (77.3\%). These methods should be recommended for diagnostic procedures in cases of abnormal cytology as the best approach for assessing the risk of development of cervical dysplasia. This statement is consistent with recommendations noted in many other studies $(15,19,21)$. We achieved the same NPV of $85.1 \%$ when conducting each test separately to detect CIN1+. The negative results of both tests were primarily observed with the CIN1 cases; thus, the NPV was $94.2 \%$ for detecting CIN2+ for the HPV tests and $96.0 \%$ for colposcopy. The reason is that we often observed the elimination of dysplasia after some time or even HPV disappearance from the cell, if the infection had been acquired a long time previously. Nevertheless, the HPV test is not recommended for patients with HSIL (NPV of $60 \%$ ), in contrast to colposcopy, where $100 \%$ of cases with a negative colposcopy were confirmed at final diagnosis. The impressive negative predictive values of $92.3 \%$ for CIN1+ and $96.1 \%$ for CIN2+ were obtained for both tests performed together. The same result was found in a Greek publication, and a very high NPV of $99.8 \%$ was reported in a study from Spain $(15,22)$. However, we believe that colposcopy performed after a negative DNA HPV test has no application in routine diagnosis because of the additional psychological stress for the patient and the higher cost of diagnosis. 
Table II. Distribution of the HPV virus genotype in 186 examined patients.

\begin{tabular}{|c|c|c|c|c|c|c|}
\hline $\begin{array}{l}\mathrm{HPV} \\
\text { type }\end{array}$ & $\begin{array}{l}\text { HSIL } \\
(n=14)\end{array}$ & $\begin{array}{c}\text { ASC-H } \\
(n=3)\end{array}$ & $\begin{array}{l}\text { LSIL } \\
(\mathrm{n}=56)\end{array}$ & $\begin{array}{c}\text { ASC-US } \\
(n=26)\end{array}$ & $\begin{array}{l}\text { Total } \\
(\mathrm{n}=99)\end{array}$ & $\begin{array}{c}\text { Total } \\
\%\end{array}$ \\
\hline \multicolumn{7}{|l|}{ HR HPV } \\
\hline 16 & 4 & 1 & 13 & 5 & 23 & $23.2 \%$ \\
\hline 18 & - & - & 2 & 1 & 3 & $3.0 \%$ \\
\hline 31 & 2 & 1 & 11 & 4 & 18 & $18.2 \%$ \\
\hline 33 & 3 & - & 6 & 2 & 11 & $11.1 \%$ \\
\hline 35 & - & - & 5 & 1 & 6 & $6.1 \%$ \\
\hline 51 & 1 & - & 3 & 1 & 5 & $5.1 \%$ \\
\hline 52 & - & - & 1 & - & 1 & $1.0 \%$ \\
\hline 56 & - & - & 1 & - & 1 & $1.0 \%$ \\
\hline 58 & 1 & - & 5 & - & 6 & $6.1 \%$ \\
\hline 67 & - & - & 2 & 1 & 3 & $3.0 \%$ \\
\hline \multicolumn{7}{|l|}{ LR HPV } \\
\hline 6 & 1 & - & 2 & 1 & 4 & $4.0 \%$ \\
\hline 11 & - & - & - & 1 & 1 & $1.0 \%$ \\
\hline 30 & 1 & - & 8 & 2 & 11 & $11.1 \%$ \\
\hline 39 & - & - & 1 & - & 1 & $1.0 \%$ \\
\hline 42 & - & 1 & - & - & 1 & $1.0 \%$ \\
\hline 53 & - & - & 1 & - & 1 & $1.0 \%$ \\
\hline 54 & - & - & 1 & - & 1 & $1.0 \%$ \\
\hline 59 & - & - & 1 & - & 1 & $1.0 \%$ \\
\hline 61 & - & - & 1 & 2 & 3 & $3 / 0 \%$ \\
\hline 62 & & 2 & 2 & 1 & 5 & $5.1 \%$ \\
\hline 66 & - & - & - & 1 & 1 & $1.0 \%$ \\
\hline $\begin{array}{l}\text { Undefined } \\
\text { HR }\end{array}$ & - & - & 3 & 2 & 5 & $5.1 \%$ \\
\hline $\begin{array}{l}\text { Undefined } \\
\text { LR }\end{array}$ & 2 & - & - & 3 & 5 & $5.1 \%$ \\
\hline
\end{tabular}

The other diagnostic parameters that we compared in the study were the sensitivity and specificity of the tests for detecting cases with any dysplasia. The specificity of the HPV test $(60.2 \%$ for CIN1+ and $52.9 \%$ for CIN2+) results from the detection of a large number of latent HPV infections that disappear after several years and do not cause any abnormal changes. This finding explains why HPV tests are more sensitive $(79.4 \%$ for CIN1+ and $83.9 \%$ for CIN2+) than specific: they detect most HPV infections, including those that are not clinically relevant. Previous studies have shown sensitivities ranging from $78 \%$ to $93 \%$ and specificities from $63 \%$ to $81 \%(15-17,22,23)$. The variance stems from the different HPV tests applied and the detection of different numbers of HPV genotypes. The colposcopy test in our study was more specific $(83.5 \%)$ than sensitive (73.7\%) only for detecting CIN1+ cases because the test detects cervical changes that already exist and demonstrate cervical neoplasia disease. A patient's colposcopy shows a higher sensitivity $(85.2 \%)$ than specificity $(72.9 \%)$ for finding CIN2+ lesions. Other studies have reported divergent results of very low sensitivity, e.g., 13\%, and a specificity of $99 \%$ for detecting CIN2/3 13 and inverse values of a high
Table III. Distribution of the final diagnosis, according to cytology group in 186 patients.

\begin{tabular}{lrrrcrr}
\hline $\begin{array}{l}\text { Abnormal } \\
\text { cytology } \\
\text { result }\end{array}$ & CIN1 & CIN2 & CIN3 & $\begin{array}{c}\text { Cervical } \\
\text { cancer IB }\end{array}$ & Normal & Total \\
\hline HSIL & 4 & 2 & 5 & 0 & 8 & 19 \\
ASC-H & 2 & 0 & 2 & 0 & 3 & 7 \\
LSIL & 18 & 7 & 11 & 1 & 48 & 85 \\
ASC-US & 8 & 3 & 0 & 0 & 60 & 71 \\
AGUS & 0 & 0 & 0 & 0 & 4 & 4 \\
Total & 32 & 12 & 18 & 1 & 123 & 186 \\
\hline
\end{tabular}

sensitivity (94\%) and limited specificity (50\%) for CIN cases (15). In summary, the HPV test with molecular typing combined with colposcopy proved to be the most efficient combination, increasing the sensitivity to $90.9 \%$ and NPV to 96.1\% in CIN2+ cases and the PPV to $77.3 \%$ in CIN1+ diagnosis, values that are in agreement with other studies $(15,21)$. These findings also suggest that the screening intervals could be safely made longer for women with a negative HPV test. This is confirmed by other publications showing that primary HPV screening could be the most efficient test in detecting patients at high risk of dysplasia or may be a method to lengthen screen intervals for women with an HPV-negative result $(17,22,24-27)$.

In the studied population, the overall HPV prevalence was $53.2 \%$. This finding is consistent with the results of previous studies on HPV infection and genotype distribution (28). The prevalence of HPV in abnormal cytology in Poland is $65.7 \%$, and in some European countries, it is $53.2 \%(13,29)$. This contrasts with a finding from a study in Italy that showed a lower prevalence of $33.8 \%$ (30). Among the positive samples, oncogenic genotypes were found in $64.6 \%$ of the patients, non-oncogenic types were observed in $19.2 \%$ and multiple infections were detected in $16.2 \%$ of cases. These findings are similar to the results from studies in the Italian population (31). The high-risk types were most frequently observed in patients with LSIL (71.4\%) and ASC-H (66.7\%), rather than among patients with HSIL (50\%). In contrast, studies from the US indicated the following distribution of oncogenic types: $50 \%$ in patients with ASCUS, 54\% in patients with LSIL, and $85 \%$ in patients with $\operatorname{HSIL}(32,33)$. However, the positive HPV test correlates well with the endof-study results, with $88.9 \%$ of patients with CIN3 having a high-risk HPV infection and $55.5 \%$ being of the HPV 16 type. Concerning the diagnosis of CIN2, we detected $75 \%$ of women with HPV infection, mostly of high-risk types. This finding is consistent with the other published studies that demonstrated that HPV 16 and other high-risk genotypes had the greatest association with CIN 2/3 dysplasia/lesion or cervical carcinoma $(3,4,34)$. 
Table IV. Distribution of colposcopic and HPV infection results, according to final diagnosis.

\begin{tabular}{|c|c|c|c|c|c|c|c|c|}
\hline \multirow{2}{*}{$\begin{array}{l}\text { Final } \\
\text { diagnosis }\end{array}$} & \multirow[t]{2}{*}{$\mathrm{N}$} & \multicolumn{3}{|c|}{ Colposcopy results } & \multirow{2}{*}{ 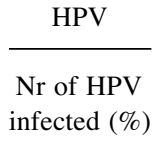 } & \multicolumn{3}{|c|}{ Distribution of HPV types } \\
\hline & & $\begin{array}{l}\text { Suspected } \\
(\%)\end{array}$ & $\begin{array}{c}\text { Negative } \\
(\%)\end{array}$ & $\begin{array}{c}\text { Unsatisfactory } \\
(\%)\end{array}$ & & $\begin{array}{l}\mathrm{HR} \\
(\%)\end{array}$ & $\begin{array}{l}\mathrm{LR} \\
(\%)\end{array}$ & $\begin{array}{c}\text { Co-infection } \\
(\%)\end{array}$ \\
\hline Cancer & 1 & $\begin{array}{c}1 \\
(100 \%)\end{array}$ & $\begin{array}{c}0 \\
(0 \%)\end{array}$ & $\begin{array}{c}0 \\
(0 \%)\end{array}$ & $\begin{array}{c}1 \\
(100 \%)\end{array}$ & $\begin{array}{c}1 \\
(100 \%)\end{array}$ & $\begin{array}{c}0 \\
(0 \%)\end{array}$ & $\begin{array}{c}0 \\
(0 \%)\end{array}$ \\
\hline CIN3 & 18 & $\begin{array}{c}15 \\
(83.3 \%)\end{array}$ & $\begin{array}{c}1 \\
(5.6 \%)\end{array}$ & $\begin{array}{c}2 \\
(11.1 \%)\end{array}$ & $\begin{array}{c}16 \\
(88.9 \%)\end{array}$ & $\begin{array}{c}12 \\
(75.0 \%)\end{array}$ & $\begin{array}{c}2 \\
(12.5 \%)\end{array}$ & $\begin{array}{c}2 \\
(12.5 \%)\end{array}$ \\
\hline CIN2 & 12 & $\begin{array}{c}7 \\
(58.3 \%)\end{array}$ & $\begin{array}{c}3 \\
(25.0 \%)\end{array}$ & $\begin{array}{c}2 \\
(16.7 \%)\end{array}$ & $\begin{array}{c}9 \\
(75.0 \%)\end{array}$ & $\begin{array}{c}7 \\
(77.8 \%)\end{array}$ & $\begin{array}{c}1 \\
(11.1 \%)\end{array}$ & $\begin{array}{c}1 \\
(11.1 \%)\end{array}$ \\
\hline CIN1 & 32 & $\begin{array}{c}19 \\
(56.25 \%)\end{array}$ & $\begin{array}{c}11 \\
(37.5 \%)\end{array}$ & $\begin{array}{c}2 \\
(6.25 \%)\end{array}$ & $\begin{array}{c}24 \\
(75.0 \%)\end{array}$ & $\begin{array}{c}13 \\
(54.2 \%)\end{array}$ & $\begin{array}{c}4 \\
(16.7 \%)\end{array}$ & $\begin{array}{c}7 \\
(29.2 \%)\end{array}$ \\
\hline Healthy & 123 & $\begin{array}{c}17 \\
(13.8 \%)\end{array}$ & $\begin{array}{c}86 \\
(69.9 \%)\end{array}$ & $\begin{array}{c}20 \\
(16.3 \%)\end{array}$ & $\begin{array}{c}49 \\
(39.8 \%)\end{array}$ & $\begin{array}{c}31 \\
(63.3 \%)\end{array}$ & $\begin{array}{c}12 \\
(24.5 \%)\end{array}$ & $\begin{array}{c}6 \\
(12.2 \%)\end{array}$ \\
\hline Total & 186 & $\begin{array}{c}59 \\
(31.7 \%)\end{array}$ & $\begin{array}{c}101 \\
(54.3 \%)\end{array}$ & $\begin{array}{c}26 \\
(14 \%)\end{array}$ & $\begin{array}{c}99 \\
(53.2 \%)\end{array}$ & $\begin{array}{c}64 \\
(64.6 \%)\end{array}$ & $\begin{array}{c}19 \\
(19.2 \%)\end{array}$ & $\begin{array}{c}16 \\
(16.2 \%)\end{array}$ \\
\hline
\end{tabular}

Table V. Comparison of the screening efficacy between colposcopy and the HPV test for CIN1+ and CIN2+.

\begin{tabular}{|c|c|c|c|c|c|c|c|c|}
\hline \multirow{2}{*}{$\begin{array}{l}\text { Test } \\
\text { Threshold } \\
\text { HPV typing }\end{array}$} & \multicolumn{2}{|c|}{ Sensitivity $\%$} & \multicolumn{2}{|c|}{ Specificity \% } & \multicolumn{2}{|c|}{ PPV \% } & \multicolumn{2}{|c|}{ NPV \% } \\
\hline & $\begin{array}{c}\text { CIN1+ } \\
79.4\end{array}$ & $\begin{array}{c}\text { CIN2+ } \\
83.9\end{array}$ & $\begin{array}{c}\text { CIN1+ } \\
6022\end{array}$ & $\begin{array}{c}\text { CIN2+ } \\
52.9\end{array}$ & $\begin{array}{c}\text { CIN1+ } \\
50.5\end{array}$ & $\begin{array}{c}\text { CIN2+ } \\
2633\end{array}$ & $\begin{array}{c}\text { CIN1+ } \\
851\end{array}$ & $\begin{array}{c}\text { CIN2+ } \\
9422\end{array}$ \\
\hline Colposcopy & 73.7 & 85.2 & 83.5 & 72.9 & 71.2 & 39.0 & 85.1 & 96.0 \\
\hline $\begin{array}{l}\text { HPV and } \\
\text { colposcopy }\end{array}$ & 89.5 & 90.9 & 82.8 & 67.6 & 77.3 & 45.4 & 92.3 & 96.1 \\
\hline
\end{tabular}

HPV 16 was the most prevalent genotype (23.2\%), followed by the oncogenic genotypes HPV 31, 33, 35 and 58 and the low-risk types 30 and 62 . In our study, the incidence of HPV 31 (18.2\%), HPV $33(11.1 \%)$ and $30(11.1 \%)$ was surprisingly high compared with the incidence of the other genotypes. Our results were consistent with those from previous studies in Poland, in which HPV 16 was found to be the most common genotype and HPV 18 was less common (12-14). A similar HPV distribution has been reported in other European countries, including Italy, Greece, Denmark, Estonia and Latvia (31, 35-38). Interestingly, genotype 45 was not observed in our study; previous studies have also found that this type is infrequent $(28,31,37,38)$.

In conclusion, the efficacy of both colposcopy and the HPV test performed together provides the best diagnostic values for the PPV, NPV and sensitivity, which makes this coupled method highly effective and accurate in detecting mild and severe CIN lesions. Moreover, the HPV test itself, when negative, might improve the identification of healthy women and allow a lengthening of the screening interval in cervical cancer prevention programs. Additionally, we found that HPV 16 was the most prevalent genotype, followed by HPV types 31,33 and 30. These results are unusual, given the results of previous studies. Further research on a larger scale is required.

\section{Conflicts of Interest}

The Authors declare no conflicts of interest.

\section{Authors' Contributions}

Joanna Świderska-Kiec: Study design, data collection, data analysis, manuscript preparation. Krzysztof Czajkowski: Study design, data analysis, manuscript preparation. Julia ZarębaSzczudlik: Data collection, data analysis, manuscript preparation. Joanna Kacperczyk-Bartnik: Data analysis, manuscript preparation. Paweł Bartnik: Data analysis, manuscript preparation. Ewa Romejko-Wolniewicz: Study design, data analysis, manuscript preparation.

\section{References}

1 Bosch FX, Lorincz A, Muñoz N, Meijer C and Shah KV: The causal relation between human papillomavirus and cervical cancer. J Clin Pathol 55(4): 244-265, 2002. PMID: 11919208. DOI: $10.1136 /$ jcp. 55.4 .244

2 de Villiers E-M: Taxonomic classification of papillomaviruses. Pap Rep 12(3): 57-63, 2001.

3 Clifford G, Smith J, Plummer M, Munoz N and Franceschi S: Human papillomavirus types in invasive cervical cancer worldwide: A meta-analysis. Br J Cancer 88(1): 63, 2003. PMID: 12556961 . DOI: $10.1038 /$ sj.bjc.6600688 
4 Clifford G, Smith J, Aguado T and Franceschi S: Comparison of HPV type distribution in high-grade cervical lesions and cervical cancer: A meta-analysis. Br J Cancer 89(1): 101, 2003. PMID: 12838308. DOI: $10.1038 /$ sj.bjc.6601024

5 Clifford G, Franceschi S, Diaz M, Munoz N and Villa LL: HPV type-distribution in women with and without cervical neoplastic diseases. Vaccine 24 (Suppl 3): 26-34, 2006. PMID: 16950015. DOI: $10.1016 /$ j.vaccine.2006.05.026

6 Brown DR, Schroeder JM, Bryan JT, Stoler MH and Fife KH: Detection of multiple human papillomavirus types in condylomata acuminata lesions from otherwise healthy and immunosuppressed patients. J Clin Microbiol 37(10): 33163322, 1999. PMID: 10488198.

7 Wiatrak BJ: Overview of recurrent respiratory papillomatosis. Curr Opin Otolaryngol Head Neck Surg 11(6): 433-441, 2003. PMID: 14631175. DOI: 10.1097/00020840-200312000-00005

8 Argyri E, Tsimplaki E, Papatheodorou D, Daskalopoulou D and Panotopoulou E: Recent trends in HPV infection and type distribution in Greece. Anticancer Res 38(5): 3079-3084, 2018. PMID: 29715143. DOI: 10.21873/anticanres.12565.

9 Van SN, Khac MN, Dimberg J, Matussek A and Henningsson AJ: Prevalence of cervical infection and genotype distribution of human papilloma virus among females in Da Nang, Vietnam. Anticancer Res 37(3): 1243-1247, 2017. PMID: 28314288. DOI: 10.21873/anticanres.11440

10 Asciutto KC, Forslund O and Borgfeldt C: Prevalence of highrisk HPV in postmenopausal women with benign cervical cytology-a population-based cohort study. Anticancer Res 38(7): 4221-4228, 2018. PMID: 29970554. DOI: 10.21873/anticanres. 12718

11 Ernstson A, Asciutto KC, Sturesson J, Noren J, Forslund O and Borgfeldt C: Detection of HPV mRNA in self-collected vaginal samples among women at 69-70 years of age. Anticancer Res 39(1): 381-386, 2019. PMID: 30591484. DOI: 10.21873/ anticanres. 13123

12 Szostek S, Klimek M, Zawilinska B and Kosz-Vnenchak M: Genotype-specific human papillomavirus detection in cervical smears. Acta Biochim Pol 55(4): 687-692, 2008. PMID: 19015776.

13 Bardin A, Vaccarella S, Clifford G, Lissowska J, Rekosz M, Bobkiewicz P, Kupryjańczyk J, Krynicki R, Jonska-Gmyrek J and Danska-Bidzinska A: Human papillomavirus infection in women with and without cervical cancer in Warsaw, Poland. Eur J Cancer 44(4): 557-564, 2008. PMID: 18191395. DOI: 10.1016/j.ejca.2007.12.001

14 Dybikowska A, Licznerski P and Podhajska A: HPV detection in cervical cancer patients in northern Poland. Oncol Rep 9(4): 871-874, 2002. PMID: 12066224.

15 Adamopoulou M, Kalkani E, Charvalos E, Avgoustidis D, Haidopoulos D and Yapijakis C: Comparison of cytology, colposcopy, HPV typing and biomarker analysis in cervical neoplasia. Anticancer Res 29(8): 3401-3409, 2009. PMID: 19661364

16 Ferris DG, Wright TC Jr., Litaker MS, Richart RM, Lorincz AT, Sun X-W, Borgatta L, Buck H, Kramer L and Rubin R: Triage of women with ascus and lsil on pap smear reports: Management by repeat Pap smear, HPV DNA testing, or colposcopy? J Fam Pract 46(2): 125-135, 1998. PMID: 9487318.

17 Schneider A, Hoyer H, Lotz B, Leistritza S, Kühne-Heid R, Nindl I, Müller B, Haerting J and Dürst M: Screening for highgrade cervical intra-epithelial neoplasia and cancer by testing for high-risk HPV, routine cytology or colposcopy. Int J Cancer 89(6): 529-534, 2000. PMID: 11102899.

18 Jeronimo J and Schiffman M: Colposcopy at a crossroads. Am J Obstet Gynecol 195(2): 349-353, 2006. PMID: 16677597. DOI: $10.1016 /$ j.ajog.2006.01.091

19 Ciotti M, Sesti F, Paba P, Benedetto A, Patrizi L, Criscuolo A, Piccione E, Branca M, Syrjänen $K$ and Favalli C: Human papillomavirus (HPV) testing in the management of women with abnormal Pap smears. Experience of a colposcopy referral clinic. Eur J Gynaecol Oncol 25(5): 577-584, 2004. PMID: 15493169.

20 Barut MU, Kale A, Kuyumcuoğlu U, Bozkurt M, Ağaçayak E, Özekinci S and Gul T: Analysis of sensitivity, specificity, and positive and negative predictive values of smear and colposcopy in diagnosis of premalignant and malignant cervical lesions. Med Sci Monit 21: 3860-3867, 2015. PMID: 26655816. DOI: $10.12659 / \mathrm{msm} .895227$

21 Monsonego J, Zerat L, Catalan F and Coscas Y: Genital human papillomavirus infections: Correlation of cytological, colposcopic and histological features with viral types in women and their male partners. Int J STD AIDS 4(1): 13-20, 1993. PMID: 8381304. DOI: 10.1177/095646249300400104

22 Ibáñez R, Autonell J, Sardà M, Crespo N, Pique P, Pascual A, Martí C, Fibla M, Gutiérrez C and Lloveras B: Protecting the underscreened women in developed countries: The value of HPV test. BMC Cancer 14(1): 574, 2014. PMID: 25102758. DOI: 10.1186/1471-2407-14-574

23 Pretorius RG, Peterson P, Novak S, Azizi F, Sadeghi M and Lorincz AT: Comparison of two signal-amplification dna tests for high-risk HPV as an aid to colposcopy. J Reprod Med 47(4): 290-296, 2002. PMID: 12012880.

24 Castle PE, Sideri M, Jeronimo J, Solomon D and Schiffman M: Risk assessment to guide the prevention of cervical cancer. Am J Obstet Gynecol 197(4): 356. e1-e6. e356, 2007. PMID: 17904958. DOI: 10.1016/j.ajog.2007.07.049

25 Chrysostomou A, Stylianou D, Constantinidou A and Kostrikis L: Cervical cancer screening programs in Europe: The transition towards HPV vaccination and population-based HPV testing. Viruses 10(12): e729, 2018. PMID: 30572620. DOI: 10.3390/v10120729

26 Lew JB, Simms K, Smith M, Lewis H, Neal H and Canfell K: Effectiveness modelling and economic evaluation of primary HPV screening for cervical cancer prevention in New Zealand. PLoS One 11(5): e0151619, 2016. PMID: 27187495. DOI: 10.1371/journal.pone.0151619.

27 Pista A, Costa C, Saldanha C, Moutinho JAF, Moutinho JM, Arrobas F, Catalão C and Kempers J: Budget impact analysis of cervical cancer screening in portugal: Comparison of cytology and primary HPV screening strategies. BMC Public Health 19(1): 235, 2019. PMID: 30808324. DOI: 10.1186/s12889-019-6536-4

28 Al-Awadhi R, Chehadeh W, Jaragh M, Al-Shaheen A, Sharma P and Kapila K: Distribution of human papillomavirus among women with abnormal cervical cytology in Kuwait. Diagn Cytopathol 41(2): 107-114, 2013. PMID: 21987449. DOI: $10.1002 / \mathrm{dc} .21778$

29 Negri G, Rigo B, Vittadello F, Mian C and Egarter-Vigl E: Abnormal cervicovaginal cytology with negative human papillomavirus testing. Cancer 111(5): 280-284, 2007. PMID: 17724678. DOI: $10.1002 /$ cncr.22952

30 Menzo S, Ciavattini A, Bagnarelli P, Marinelli K, Sisti S and Clementi M: Molecular epidemiology and pathogenic potential of 
underdiagnosed human papillomavirus types. BMC Microbiol $8(1)$ : 112, 2008. PMID: 18601724. DOI: 10.1186/1471-2180-8-112

31 Menegazzi P, Barzon L, Palu G, Reho E and Tagliaferro L: Human papillomavirus type distribution and correlation with cyto-histological patterns in women from the south of Italy. Inf Dis Obstet Gynecol 2009: 198425. PMID: 20145716. DOI: $10.1155 / 2009 / 198425$

32 Evans MF, Adamson CSC, Papillo JL, St. John TL, Leiman G and Cooper K: Distribution of human papillomavirus types in thinprep papanicolaou tests classified according to the Bethesda 2001 terminology and correlations with patient age and biopsy outcomes. Cancer 106(5): 1054-1064, 2006. PMID: 16421920. DOI: $10.1002 /$ cncr.21664

33 Santos ALF, Derchain SFM, Martins MR, Sarian LOZ, Martinez EZ and Syrjänen KJ: Human papillomavirus viral load in predicting high-grade CIN in women with cervical smears showing only atypical squamous cells or low-grade squamous intraepithelial lesion. Sao Paulo Med J 121(6): 238-243, 2003 PMID: 14989139. DOI: 10.1590/s1516-31802003000600004

34 Huang LW, Lin YH, Pan HS, Seow KM and Lin CY: Human papillomavirus genotyping as a predictor of high-grade cervical dysplasia in women with mildly cytologic abnormalities: A twoyear follow-up report. Diagn Cytopathol 40(8): 673-677, 2012. PMID: 21442773. DOI: $10.1002 / \mathrm{dc} .21591$

35 Uusküla A, Kals M, Kosenkranius L, McNutt L-A and DeHovitz $\mathrm{J}$ : Population-based type-specific prevalence of high-risk human papillomavirus infection in Estonia. BMC Infect Dis 10(1): 63, 2010. PMID: 20222944. DOI: 10.1186/1471-2334-10-63
36 Stamataki P, Papazafiropoulou A, Elefsiniotis I, Giannakopoulou M, Brokalaki H, Apostolopoulou E, Sarafis P and Saroglou G: Prevalence of HPV infection among greek women attending a gynecological outpatient clinic. BMC Infect Dis 10(1): 27, 2010. PMID: 20156352. DOI: 10.1186/1471-2334-10-27

37 Clifford GM, Rana RK, Franceschi S, Smith JS, Gough G and Pimenta JM: Human papillomavirus genotype distribution in low-grade cervical lesions: Comparison by geographic region and with cervical cancer. Cancer Epidemiol Biomarkers Prev 14(5): 1157-1164, 2005. PMID: 15894666. DOI: 10.1158/10559965.EPI-04-0812

38 Rossi PG, Bisanzi S, Paganini I, Di Iasi A, Angeloni C, Scalisi A, Macis R, Pini MT, Chini F and Carozzi FM: Prevalence of HPV high and low risk types in cervical samples from the Italian general population: A population based study. BMC Infect Dis 10(1): 214, 2010. PMID: 20646310. DOI: 10.1186/1471-233410-214.

Received January 15, 2020

Revised February 2, 2020

Accepted February 3, 2020 